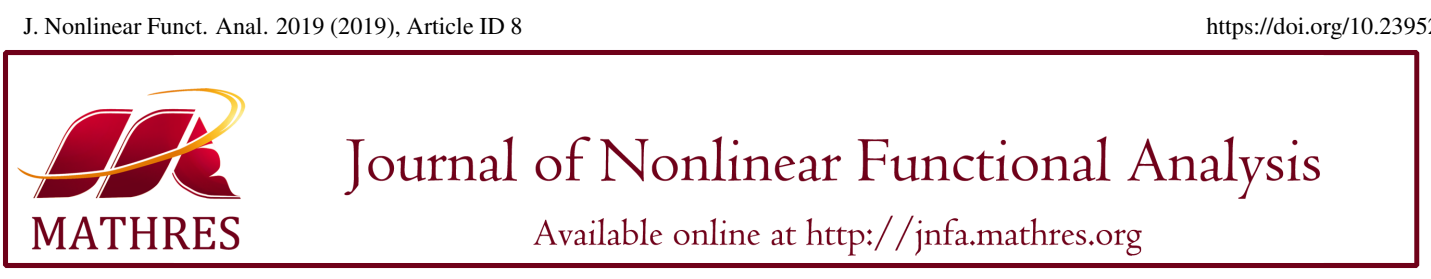

https://doi.org/10.23952/jnfa.2019.8

\title{
THREE KINDS OF HYBRID ALGORITHMS AND THEIR NUMERICAL REALIZATIONS FOR A FINITE FAMILY OF QUASI-NONEXPANSIVE MAPPINGS
}

\author{
LERONG MA ${ }^{1}$, XINGHUI GAO ${ }^{1, *}$, HAIYUN ZHOU ${ }^{2}$ \\ ${ }^{1}$ College of Mathematics and Computer Science, Yan'an University, Shaanxi 716000, China \\ ${ }^{2}$ Department of Mathematics, Shijiazhuang Mechanical Engineering College, Shijiazhuang 050003, China
}

\begin{abstract}
The purpose of this paper is to propose three new hybrid projection methods for a finite family of quasi-nonexpansive mappings. The strong convergence of the algorithms is proved in real Hilbert spaces. Some numerical experiments are also provided to compare and illustrate the effectiveness of the proposed algorithm.
\end{abstract}

Keywords. Quasi-nonexpansive mapping; Hybrid algorithms; Strong convergence; Numerical experiments.

2010 Mathematics Subject Classification. 47H05, 47H09, 47H10.

\section{INTRODUCTION}

Suppose that $H$ is a real Hilbert space and $C$ is a closed convex nonempty subset of $H$. We use $\langle\cdot, \cdot\rangle$ and $\|\cdot\|$ to denote the inner product and the norm, respectively. Let $T: C \rightarrow C$ be a mapping. We use $F(T)$ to denote the fixed-point set of $T$, i.e., $F(T)=\{x \in C: x=T x\}$. Recall that $T: C \rightarrow C$ is called a nonexpansive mappings if

$$
\|T x-T y\| \leq\|x-y\|, \quad \forall x, y \in C .
$$

Recall that $T: C \rightarrow C$ is called a quasi-nonexpansive mapping if $F(T) \neq \emptyset$ and

$$
\|T x-p\| \leq\|x-p\|, \quad x \in C, p \in F(T)
$$

Obviously, a nonexpansive mapping with a nonempty fixed point set $F(T)$ is a quasi-nonexpansive mapping, but the converse may be not true. Since common fixed-point problems have a lot of real world applications, such as image recovery, and signal processing [1, 2, 3], the construction of common fixed points for a finite family of nonlinear mappings is of practical importance. In particular, iterative algorithms for finding common fixed points of a finite family of nonexpansive mappings have been extensively studied; see $[4,5,6,7]$ and the references therein

${ }^{*}$ Corresponding author.

E-mail addresses: mlr@yau.edu.cn (L. Ma), yadxgaoxinghui@163.com (X. Gao), zhouhy123@aliyun.com (H. Zhou).

Received August 22, 2018; Accepted February 22, 2019.

(C)2019 Journal of Nonlinear Functional Analysis 
In 2003, Nakajo and Takahashi [8] first introduced a hybrid algorithm for fixed points of nonexpansive mappings. Thereafter, some hybrid algorithms have been studied extensively since they have strong convergence without any compact assumptions; see, for example, $[9,10,11,12,13]$ and the references therein.

Recently, Anh and Chung [14] proposed a parallel hybrid algorithm for a finite family of nonexpansive mappings $\left\{T_{1}, T_{2}, \ldots, T_{N}\right\}$ in a Hilbert space $H$ as following:

$$
\left\{\begin{array}{l}
x_{0} \in C \text { chosen arbitrarily, } \\
z_{k}=P_{C}\left(x_{k}\right) \\
y_{k}^{i}=\alpha_{k} z_{k}+\left(1-\alpha_{k}\right) T_{i}\left(z_{k}\right), i=1,2, \cdots, N \\
i_{k}=\arg \max \left\{\left\|y_{k}^{i}-x_{k}\right\|: i=1,2, \cdots, N\right\} \\
C_{k}=\left\{v \in H:\left\|v-y_{k}^{i_{k}}\right\| \leq\left\|v-x_{k}\right\|\right\} \\
Q_{k}=\left\{u \in H:\left\langle x_{0}-x_{k}, x_{k}-u\right\rangle \geq 0\right\} \\
x_{k+1}=P_{C_{k} \cap Q_{k}}\left(x_{0}\right)
\end{array}\right.
$$

They proved that $\left\{x_{n}\right\}$ strongly converges to a particular common fixed points of $T_{1}, T_{2}, \cdots, T_{N}, P_{\bigcap_{i=1}^{N} F\left(T_{i}\right)} x_{0}$ in the framework of Hilbert spaces.

Very recently, Dong, Lu and Yang [15] proposed a cyclic algorithm for a finite family of nonexpansive mappings $\left\{T_{1}, T_{2}, \ldots, T_{N}\right\}$ in a Hilbert space $H$ as following:

$$
\left\{\begin{array}{l}
x_{0} \in C \text { chosen arbitrarily, } \\
y_{k}^{1}=\alpha_{k} x_{k}+\left(1-\alpha_{k}\right) T_{1}\left(x_{k}\right), \\
y_{k}^{i+1}=\alpha_{k} y_{k}^{i}+\left(1-\alpha_{k}\right) T_{i+1}\left(y_{k}^{i}\right), i=1,2, \cdots, N-1, \\
i_{k}=\arg \max \left\{\left\|y_{k}^{i}-x_{k}\right\|: i=1,2, \cdots, N\right\} \\
C_{k}=\left\{u \in C:\left\|u-y_{k}^{i}\right\| \leq\left\|u-x_{k}\right\|\right\} \\
Q_{k}=\left\{v \in C:\left\langle x_{0}-x_{k}, x_{k}-v\right\rangle \geq 0\right\} \\
x_{k+1}=P_{C_{k} \cap Q_{k}}\left(x_{0}\right) .
\end{array}\right.
$$

They proved that $\left\{x_{n}\right\}$ strongly converges to a particular common fixed points of $T_{1}, T_{2}, \cdots, T_{N}, P_{\bigcap_{i=1}^{N} F\left(T_{i}\right)} x_{0}$ in the framework of Hilbert spaces.

In this paper, motivated by Anh and Dong's results, we design three simple hybrid methods for a finite family of quasi-nonexpansive mappings. Some strong convergence theorems are obtained by using new methods. We also give some numerical experiments to compare and illustrate the effectiveness of the proposed algorithms. The results obtained in this paper improve and extend the related ones obtained by many authors recently.

\section{PRELIMINARIES}

In this section, we mainly give some necessary lemmas.

The following two lemmas are trivial.

Lemma 2.1. Let $C$ be a closed convex subset of real Hilbert space $H$. Given $x \in H$ and $z \in C$. Then $z=P_{C} x$ if and only if there holds the relation $\langle x-z, y-z\rangle \leq 0, y \in C$. 
Lemma 2.2. Let $C$ be a closed convex nonempty subset of $H$ and let $P_{C}$ be the projection from $H$ onto $C$. Then

$$
\left\|y-P_{C} x\right\|^{2}+\left\|x-P_{C} x\right\|^{2} \leq\|x-y\|^{2}, x \in H, y \in C .
$$

Lemma 2.3. [16] Let $H$ be a Hilbert space. Then the following equality holds

$$
\left\|\sum_{i=1}^{n} \alpha_{i} x_{i}\right\|^{2}=\sum_{i=1}^{n} \alpha_{i}\left\|x_{i}\right\|^{2}-\sum_{1 \leq i<j \leq n} \alpha_{i} \alpha_{j}\left\|x_{i}-x_{j}\right\|^{2}
$$

where $x_{i} \in H$ and $\alpha_{i} \in[0,1](i=1,2, \cdots, n)$ such that $\sum_{i=1}^{n} \alpha_{i}=1$.

Lemma 2.4. [17] Let $C$ be a closed convex nonempty subset of $H, T: C \rightarrow C$ be a quasi-nonexpansive mapping. Then $F(T)$ is a convex closed subset of $C$.

\section{MAin Results}

Theorem 3.1. Let $C$ is a closed convex nonempty subset of a real Hilbert space H. Let $\left\{T_{i}\right\}_{i=1}^{N}: C \rightarrow C$ be a finite family of closed quasi-nonexpansive mappings such that $F=\bigcap_{i=1}^{N} F\left(T_{i}\right)$ is not empty. Let $\left\{x_{n}\right\}$ be a sequence generated by the following iterative process:

$$
\left\{\begin{array}{l}
x_{0} \in H \text { chosen arbitrarily, } \\
C_{1}=C \\
y_{n}^{1}=\alpha_{n} x_{n}+\left(1-\alpha_{n}\right) T_{1}\left(x_{n}\right) \\
y_{n}^{i+1}=\alpha_{n} y_{n}^{i}+\left(1-\alpha_{n}\right) T_{i+1}\left(y_{n}^{i}\right), i=1,2, \cdots, N-1, \\
i_{n}=\arg \max \left\{\left\|y_{n}^{i}-x_{n}\right\|: i=1,2, \cdots, N\right\} \\
C_{n+1}=\left\{w \in C_{n}:\left\|w-y_{n}^{i_{n}}\right\| \leq\left\|w-x_{n}\right\|\right\} \\
x_{n+1}=P_{C_{n+1}}\left(x_{0}\right)
\end{array}\right.
$$

where $\left\{\alpha_{n}\right\}$ is a real sequence in $(0, \alpha]$, where $\alpha$ is a real number such that $\alpha<1$. Then $\left\{x_{n}\right\}$ strongly converges to $P_{F} x_{0}$.

Proof. By Lemma 2.4 and assumpiton $F \neq \emptyset$, we know that $P_{F} x_{0}$ is well defined for every $x_{0} \in C$. From the constructions of $C_{n}$, one easily see that $C_{n}$ is closed and convex, $\forall n \geq 1$.

Next, we split our proof into five steps.

Step 1. Show that $F \subset C_{n}$ for all $n \geq 1$. 
It is obvious that $F \subset C_{1}=C$. Assume that $F \subset C_{n}$ for some $n \geq 1$. For any $q \in F \subset C_{n}$, from (3.1), we have

$$
\begin{aligned}
\left\|q-y_{n}^{i_{n}}\right\| & =\left\|q-\left\{\alpha_{n} y_{n}^{i_{n}-1}+\left(1-\alpha_{n}\right) T_{i} y_{n}^{i_{n}-1}\right\}\right\| \\
& \leq \alpha_{n}\left\|q-y_{n}^{i_{n}-1}\right\|+\left(1-\alpha_{n}\right)\left\|q-T_{i} y_{n}^{i_{n}-1}\right\| \\
& \leq \alpha_{n}\left\|q-y_{n}^{i_{n}-1}\right\|+\left(1-\alpha_{n}\right)\left\|q-y_{n}^{i_{n}-1}\right\| \\
& =\left\|q-y_{n}^{i_{n}-1}\right\| \\
& \leq \cdots \\
& \leq\left\|q-y_{n}^{1}\right\| \\
& \leq\left\|q-x_{n}\right\| .
\end{aligned}
$$

Therefore $q \in C_{n+1}$ and hence $F \subset C_{n}$ for all $n \geq 1$.

Step 2. Show that $\lim _{n \rightarrow \infty}\left\|x_{n}-x_{0}\right\|$ exists.

In view of (3.1), one has $x_{n}=P_{C_{n}}\left(x_{0}\right)$. Since $C_{n+1} \subset C_{n}$ and $x_{n+1} \in C_{n+1}$, for all $n \geq 1$, one has

$$
\left\|x_{n}-x_{0}\right\| \leq\left\|x_{n+1}-x_{0}\right\|, \forall n \geq 1 .
$$

On the other hand, as $F \subset C_{n}$ by step 1, one concludes that

$$
\left\|x_{n}-x_{0}\right\| \leq\left\|z-x_{0}\right\|, \forall z \in F, \forall n \geq 1 .
$$

Combining (3.2) and (3.3), one sees that $\lim _{n \rightarrow \infty}\left\|x_{n}-x_{0}\right\|$ exists.

Step 3. Show that $x_{n} \rightarrow v$ as $n \rightarrow \infty, v \in C$.

For $m>n \geq 1$, one has $x_{m}=P_{C_{m}}\left(x_{0}\right) \in C_{m} \subset C_{n}$. By Lemma 2.2, one has

$$
\left\|x_{m}-x_{n}\right\|^{2} \leq\left\|x_{m}-x_{0}\right\|^{2}-\left\|x_{n}-x_{0}\right\|^{2} .
$$

Taking $m, n \rightarrow \infty$ in (3.4), one gets $x_{m}-x_{n} \rightarrow 0$ as $m, n \rightarrow \infty$, which proves that $\left\{x_{n}\right\}$ is a Cauchy sequence in $C$. By completeness of space $H$ and closedness of set $C$, one can assume that $x_{n} \rightarrow v$ as $n \rightarrow \infty$.

Step 4. Show that $x_{n}-T_{i} x_{n} \rightarrow 0(n \rightarrow \infty), i=1,2, \cdots, N$.

Since $x_{n} \rightarrow v(n \rightarrow \infty)$, one has

$$
\left\|x_{n+1}-x_{n}\right\| \rightarrow 0(n \rightarrow \infty)
$$

Since $x_{n+1} \in C_{n+1}$, one has

$$
\left\|x_{n+1}-y_{n}^{i_{n}}\right\| \leq\left\|x_{n+1}-x_{n}\right\|,
$$

which implies from (3.5) that

$$
\begin{aligned}
\left\|x_{n}-y_{n}^{i_{n}}\right\| & \leq\left\|x_{n+1}-x_{n}\right\|+\left\|x_{n+1}-y_{n}^{i_{n}}\right\| \\
& \leq 2\left\|x_{n+1}-x_{n}\right\| \rightarrow 0(n \rightarrow \infty) .
\end{aligned}
$$

By the definition of $i_{n}$, one has

$$
\left\|x_{n}-y_{n}^{i}\right\| \rightarrow 0(n \rightarrow \infty), i=1,2, \cdots, N,
$$


which yields that

$$
\left\|y_{n}^{i+1}-y_{n}^{i}\right\| \leq\left\|y_{n}^{i+1}-x_{n}\right\|+\left\|y_{n}^{i}-x_{n}\right\| \rightarrow 0(n \rightarrow \infty), i=1,2, \cdots, N-1 .
$$

Using (3.1), one has

$$
\left\|x_{n}-T_{1} x_{n}\right\|=\frac{1}{1-\alpha_{n}}\left\|y_{n}^{1}-x_{n}\right\| \rightarrow 0(n \rightarrow \infty)
$$

and

$$
\left\|y_{n}^{i}-T_{i+1} y_{n}^{i}\right\|=\frac{1}{1-\alpha_{n}}\left\|y_{n}^{i}-y_{n}^{i+1}\right\| \rightarrow 0(n \rightarrow \infty), i=1,2, \cdots, N-1 .
$$

Note that $T_{i}$ is quasi-nonexpansive. By (3.6) and (3.8), one gets that

$$
\begin{aligned}
\left\|x_{n}-T_{i+1} x_{n}\right\| & \leq\left\|x_{n}-y_{n}^{i}\right\|+\left\|y_{n}^{i}-T_{i+1} y_{n}^{i}\right\|+\left\|T_{i+1} x_{n}-T_{i+1} y_{n}^{i}\right\| \\
& \leq 2\left\|x_{n}-y_{n}^{i}\right\|+\left\|y_{n}^{i}-T_{i+1} y_{n}^{i}\right\| .
\end{aligned}
$$

This implies from (3.6) and (3.8) that

$$
\left\|x_{n}-T_{i+1} x_{n}\right\| \rightarrow 0, i=1,2, \cdots, N-1 .
$$

Step 5. Show that $v=P_{F} x_{0}$.

From step 3, one knows that $x_{n} \rightarrow v(n \rightarrow \infty)$. By (3.7), (3.9) and closedness of $T_{i}$, one has $v=T_{i} v, i=$ $1,2, \cdots, N$. Therefore $v \in F$. Note that $F \subset C_{n}$ and $x_{n}=P_{C_{n}} x_{0}$. By Lemma 2.1, one concludes that

$$
\left\langle z-x_{n}, x_{0}-x_{n}\right\rangle \leq 0, \forall z \in F \text {. }
$$

It follows that

$$
\left\langle z-v, x_{0}-v\right\rangle \leq 0, \forall z \in F .
$$

By Lemma 2.1, one concludes that $v=P_{F} x_{0}$.

Remark 3.2. Theorem 3.1 generalizes the main result obtained in [15] as follows:

(i) Nonexpansive mappings are extended to quasi-nonexpansive mappings.

(ii) Iterative algorithm (3.1) is more simple than iterative algorithm (1.2), that is, there is no set " $Q_{n}$ " in iterative algorithm (3.1).

Theorem 3.3. Let $C$ be a closed convex nonempty subset of a real Hilbert space $H$. Let $\left\{T_{i}\right\}_{i=1}^{N}: C \rightarrow C$ be a finite family of closed quasi-nonexpansive mappings such that $F=\bigcap_{i=1}^{N} F\left(T_{i}\right)$ is not empty. Let $\left\{x_{n}\right\}$ be a sequence generated by the following iterative process:

$$
\left\{\begin{array}{l}
x_{0} \in H \text { chosen arbitrarily, } \\
C_{1}=C, \\
y_{n}^{i}=\alpha_{n} x_{n}+\left(1-\alpha_{n}\right) T_{i} x_{n}, i=1,2, \cdots, N, \\
i_{n}=\arg \max \left\{\left\|y_{n}^{i}-x_{n}\right\|: i=1,2, \cdots, N\right\}, \\
C_{n+1}=\left\{w \in C_{n}:\left\|w-y_{n}^{i_{n}}\right\| \leq\left\|w-x_{n}\right\|\right\}, \\
x_{n+1}=P_{C_{n+1}}\left(x_{0}\right),
\end{array}\right.
$$

where $\left\{\alpha_{n}\right\}$ is a real sequence in $(0, \alpha]$, where $\alpha$ is a real number such that $\alpha<1$. Then $\left\{x_{n}\right\}$ strongly converges to $P_{F} x_{0}$. 
Proof. The proof is also split into five steps. Steps 1, 2 and 3 are similar to the proof in Theorem 3.1. So, we omit them here. Next we prove that $x_{n}-T_{i} x_{n} \rightarrow 0(n \rightarrow \infty), i=1,2, \cdots, N$. Since $x_{n} \rightarrow v(n \rightarrow \infty)$, one has

$$
\left\|x_{n+1}-x_{n}\right\| \rightarrow 0(n \rightarrow \infty)
$$

Since $x_{n+1} \in C_{n+1}$, one has

$$
\left\|x_{n+1}-y_{n}^{i_{n}}\right\| \leq\left\|x_{n+1}-x_{n}\right\|
$$

It follows that

$$
\begin{aligned}
\left\|x_{n}-y_{n}^{i_{n}}\right\| & \leq\left\|x_{n+1}-x_{n}\right\|+\left\|x_{n+1}-y_{n}^{i_{n}}\right\| \\
& \leq 2\left\|x_{n+1}-x_{n}\right\| \rightarrow 0(n \rightarrow \infty) .
\end{aligned}
$$

By the definition of $i_{n}$, one has

$$
\left\|x_{n}-y_{n}^{i}\right\| \rightarrow 0(n \rightarrow \infty), i=1,2, \cdots, N
$$

Using (3.10), one has

$$
\left\|x_{n}-T_{i} x_{n}\right\|=\frac{1}{1-\alpha_{n}}\left\|y_{n}^{i}-x_{n}\right\| \rightarrow 0(n \rightarrow \infty),
$$

The remainder of the proof follows from Step 5 in Theorem 3.1. This completes the proof.

Remark 3.4. Theorem 3.3 generalizes the related results obtained in [14] as follows:

(i) Nonexpansive mappings are extended to quasi-nonexpansive mappings.

(ii) Iterative algorithm (3.10) is more simple than iterative algorithm (1.1), i.e., there is no set " $Q_{n}$ " in iterative algorithm (3.10).

Finally, we give another kind of a parallel iterative algorithm for a finite family of quasi-nonexpansive mappings.

Theorem 3.5. Let $C$ be a closed convex nonempty subset of a real Hilbert space $H$. Let $\left\{T_{i}\right\}_{i=1}^{N}: C \rightarrow C$ be a finite family of closed quasi-nonexpansive mappings such that $F=\bigcap_{i=1}^{N} F\left(T_{i}\right)$ is not empty. Let $\left\{x_{n}\right\}$ be a sequence generated by the following iterative process:

$$
\left\{\begin{array}{l}
x_{0} \in H \text { chosen arbitrarily, } \\
C_{1}=C, \\
y_{n}=\alpha_{n_{0}} x_{n}+\alpha_{n_{1}} T_{1} x_{n}+\cdots+\alpha_{n_{N}} T_{N} x_{n}, \\
C_{n+1}=\left\{w \in C_{n}:\left\|y_{n}-w\right\| \leq\left\|x_{n}-w\right\|\right\}, \\
x_{n+1}=P_{C_{n+1}}\left(x_{0}\right),
\end{array}\right.
$$

where $\alpha_{n_{i}}$ is a real sequence in $[0,1], i=0,1,2, \cdots, N$ such that $\alpha_{n_{0}}+\alpha_{n_{1}}+\cdots+\alpha_{n_{N}}=1$ and $\liminf _{n \rightarrow \infty} \alpha_{n_{0}} \alpha_{n_{i}}>0$. Then $\left\{x_{n}\right\}$ strongly converges to $P_{F} x_{0}$.

Proof. As shown in Theorem 3.1, one has that $P_{F} x_{0}$ is well defined for every $x_{0} \in H$, and $C_{n}$ is closed and convex. 
Next, one proves that $F \subset C_{n}, \forall n \geq 1$. For $q \in F$, one has

$$
\begin{aligned}
\left\|y_{n}-q\right\| & =\left\|\alpha_{n_{0}} x_{n}+\alpha_{n_{1}} T_{1} x_{n}+\cdots+\alpha_{n_{N}} T_{N} x_{n}-q\right\| \\
& \leq \alpha_{n_{0}}\left\|x_{n}-q\right\|+\alpha_{n_{1}}\left\|T_{1} x_{n}-q\right\|+\cdots+\alpha_{n_{N}}\left\|T_{N} x_{n}-q\right\| \\
& \leq\left\|x_{n}-q\right\|,
\end{aligned}
$$

which implies that $q \in C_{n+1}$. Therefore $\left\{x_{n}\right\}$ is well defined, $\forall n \geq 1$. Furthermore, $\lim _{n \rightarrow \infty}\left\|x_{n}-x_{0}\right\|$ exists. Hence, $x_{n} \rightarrow v(n \rightarrow \infty), v \in C$.

Next, we prove that $x_{n}-T_{i} x_{n} \rightarrow 0(n \rightarrow \infty), i=1,2, \cdots, N$. Since $x_{n} \rightarrow v(n \rightarrow \infty)$, one has

$$
\lim _{n \rightarrow \infty}\left\|x_{n+1}-x_{n}\right\|=0
$$

Since $x_{n+1} \in C_{n+1}$, one has

$$
\left\|x_{n+1}-y_{n}\right\| \leq\left\|x_{n+1}-x_{n}\right\|
$$

It follows that

$$
\left.\left\|x_{n}-y_{n}\right\| \leq\left\|x_{n+1}-x_{n}\right\|+\left\|x_{n+1}-y_{n}\right\| \leq 2\left\|x_{n+1}-x_{n}\right\| \rightarrow 0 \quad \text { (as } n \rightarrow \infty\right) \text {. }
$$

Note that $T_{i}$ is quasi-nonexpansive. For $w \in F$, we obtain from (3.11) and Lemma 2.3 that

$$
\begin{aligned}
\left\|y_{n}-w\right\|^{2} & =\left\|\alpha_{n_{0}}\left(x_{n}-w\right)+\alpha_{n_{1}}\left(T_{1} x_{n}-w\right)+\cdots+\alpha_{n_{N}}\left(T_{N} x_{n}-w\right)\right\|^{2} \\
& =\alpha_{n_{0}}\left\|x_{n}-w\right\|^{2}+\sum_{i=1}^{N} \alpha_{n_{i}}\left\|T_{i} x_{n}-w\right\|^{2}-\alpha_{n_{0}} \alpha_{n_{i}}\left\|T_{i} x_{n}-x_{n}\right\|^{2} \\
& \leq\left\|x_{n}-w\right\|^{2}-\alpha_{n_{0}} \alpha_{n_{i}}\left\|T_{i} x_{n}-x_{n}\right\|^{2} .
\end{aligned}
$$

Hence

$$
\alpha_{n_{0}} \alpha_{n_{i}}\left\|T_{i} x_{n}-x_{n}\right\|^{2} \leq\left\|x_{n}-w\right\|^{2}-\left\|y_{n}-w\right\|^{2} .
$$

By (3.12), one has

$$
\begin{aligned}
\left\|x_{n}-w\right\|^{2}-\left\|y_{n}-w\right\|^{2} & =\left\langle x_{n}-w, x_{n}-w\right\rangle-\left\langle y_{n}-w, y_{n}-w\right\rangle \\
& =\left\|x_{n}\right\|^{2}-\left\|y_{n}\right\|^{2}-2\left\langle x_{n}-y_{n}, w\right\rangle \\
& \leq\left(\left\|x_{n}\right\|+\left\|y_{n}\right\|\right)\left(\left\|x_{n}-y_{n}\right\|\right)+2\left\|x_{n}-y_{n}\right\| \cdot\|w\| \rightarrow 0(n \rightarrow \infty) .
\end{aligned}
$$

Since $\liminf _{n \rightarrow \infty} \alpha_{n_{0}} \alpha_{n_{i}}>0$, one has

$$
\left\|T_{i} x_{n}-x_{n}\right\| \rightarrow 0(n \rightarrow \infty), i=1,2, \cdots, N .
$$

The remainder of the proof follows from Step 5 in Theorem 3.1. This completes the proof. 


\section{RATE OF CONVERGENCE AND NUMERICAL EXPERIMENTS}

In this section, we provide some numerical examples to show that our algorithms are effective. We also compare the rate of convergence of these algorithms. In order to compare two fixed point iteration, Rhoades [18] introduced the following concept in 1976.

Definition 4.1. [18] Let $\left\{x_{n}\right\},\left\{z_{n}\right\}$ be two iteration schemes which converge to the same fixed point $p$. We say that $\left\{x_{n}\right\}$ is better than $\left\{z_{n}\right\}$ if $\left\|x_{n}-p\right\| \leq\left\|z_{n}-p\right\|$ for all $n$.

Berinde [19] introduced the following definition, which is slightly different from definition 4.1.

Definition 4.2. [19] Let $\left\{a_{n}\right\}_{n=0}^{\infty},\left\{b_{n}\right\}_{n=0}^{\infty}$ be two sequences of real numbers that converge to $a$ and $b$, respectively, and assume that there exists

$$
l=\lim _{n \rightarrow \infty} \frac{\left|a_{n}-a\right|}{\left|b_{n}-b\right|} .
$$

(a) If $l=0$, then it can be said that $\left\{a_{n}\right\}_{n=0}^{\infty}$ converges faster to $a$ than $\left\{b_{n}\right\}_{n=0}^{\infty}$ to $b$.

(b) If $0<l<\infty$, then it can be said that $\left\{a_{n}\right\}_{n=0}^{\infty}$ and $\left\{b_{n}\right\}_{n=0}^{\infty}$ have the same rate of convergence.

Phuengrattana and Suantai [20] presented numerical examples to compare the convergence speed of Mann, Ishikawa, Noor and SP-iterations based on the Definition 4.1.

Motivated by the above results, we present numerical examples to compare the convergence speed of algorithms (3.1), (3.10), and (3.11) by using the Definition 4.1, the Definition 4.2 and other methods. In the numerical experiments, we take the mapping $T_{1}, T_{2}: C \rightarrow \mathbb{R}$ by

$$
T_{1} x=\frac{1}{2} x \cos x, T_{2} x=\frac{2}{3} x \sin x, x \in C,
$$

where $C=[0,2 \pi], \mathbb{R}$ denotes the set of real numbers. One has that $F\left(T_{1}\right)=F\left(T_{2}\right)=\{0\}$ and $T_{1}$ and $T_{2}$ are two quasi-nonexpansive mappings. Obviously, $F\left(T_{1}\right) \cap F\left(T_{2}\right)=\{0\}$. Algorithms (3.1), (3.10), and (3.11) are iterated to step 70 respectively.

For algorithms (3.1), and (3.10), we take $\alpha_{n}=0.1$. For algorithm (3.11), we take $\alpha_{n_{0}}=0.1, \alpha_{n_{1}}=0.2$. We choose $x_{0} \in[0,2 \pi]$ arbitrarily. Then, for 50 different initial values, one can see all the results are convergent in Figure 1, Figure 2 and Figure 3.

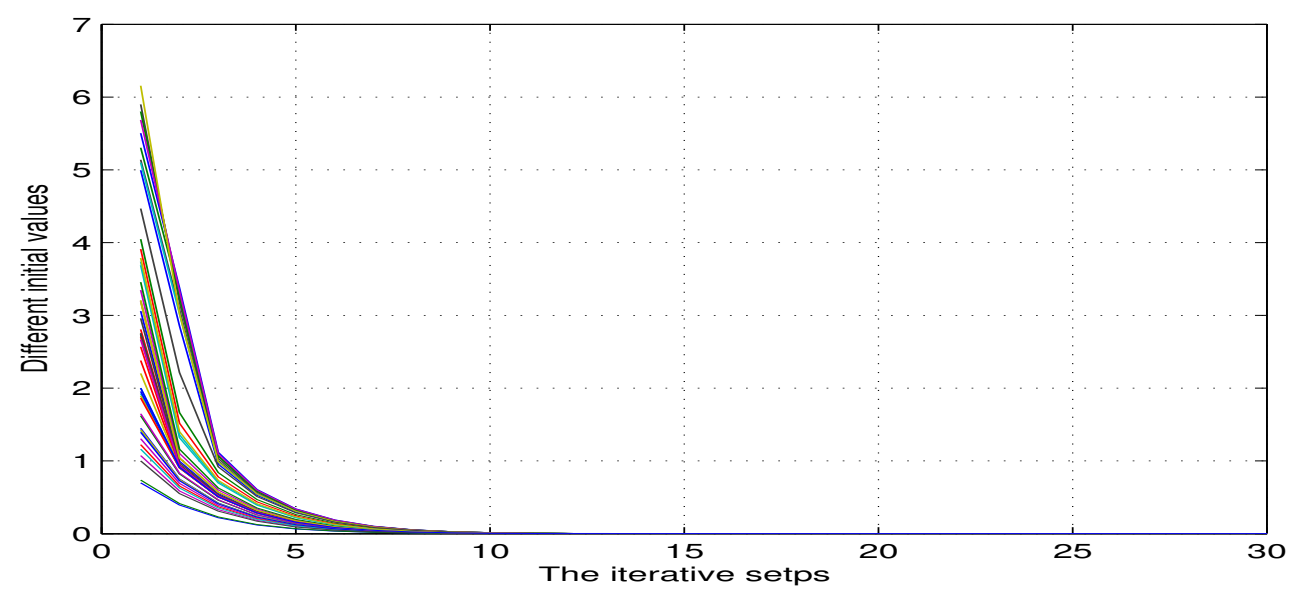

Figure 1. The iterative curves of algorithm (3.1) under different initials. 


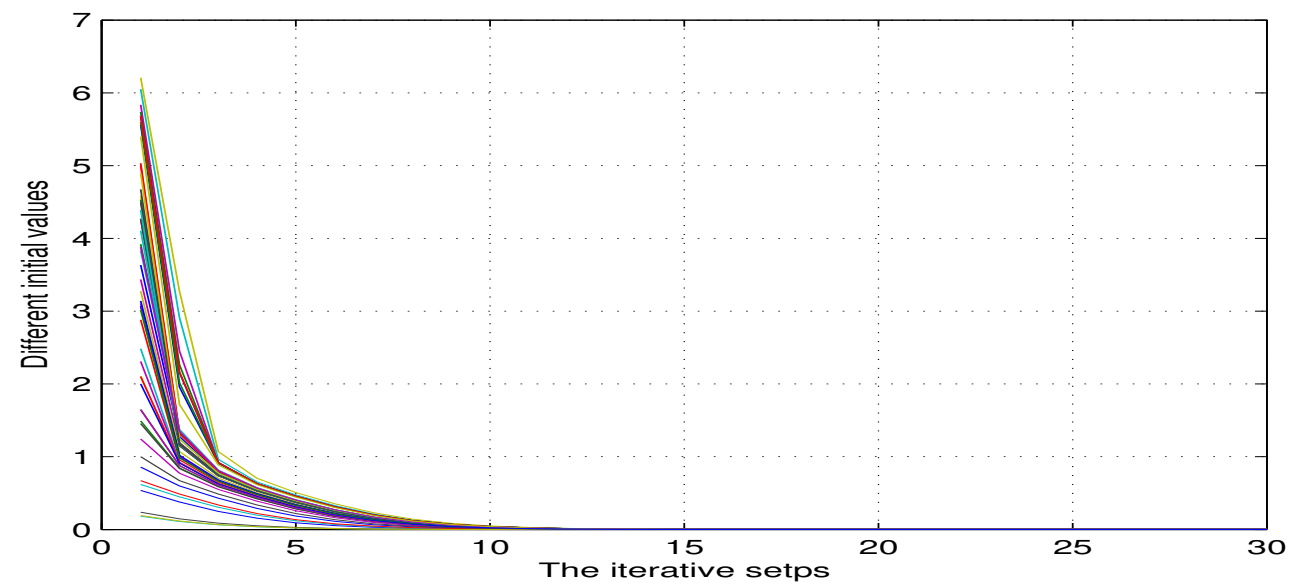

Figure 2. The iterative curves of algorithm (3.10) under different initials.

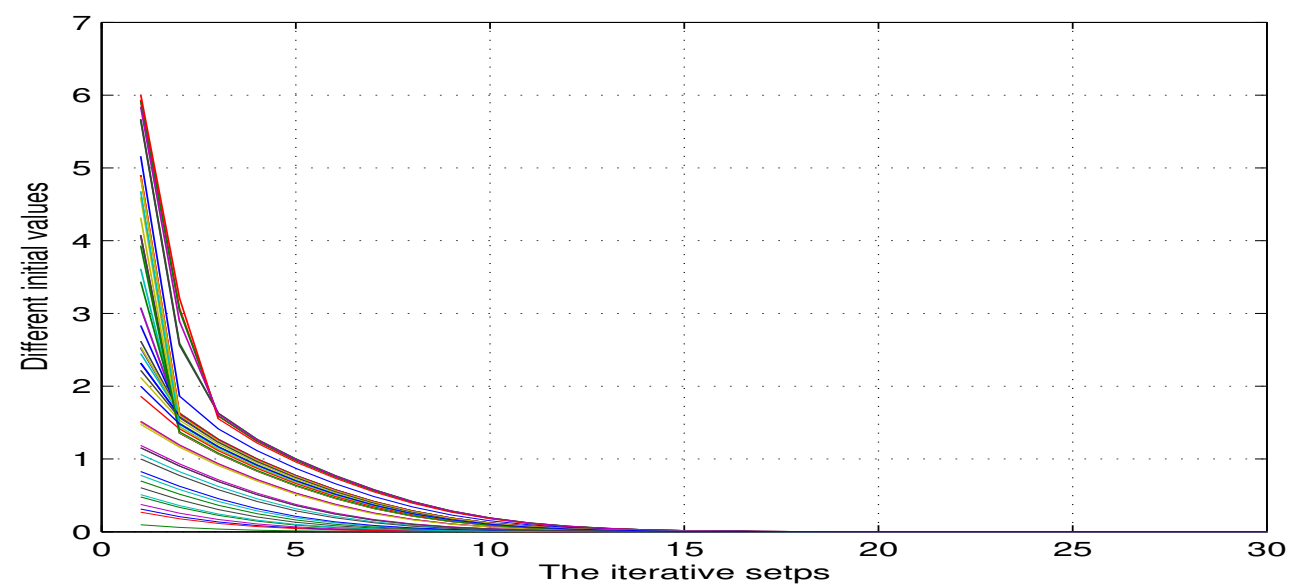

Figure 3. The iterative curves of algorithm (3.11) under different initials.

Next, we compare algorithms (3.1), (3.10), and (3.11) for the above given examples. In the following Table 1, Iter. and Sec. denote the number of iterations and the running time in seconds, respectively. We chose $x_{0} \in[0,2 \pi]$ as initial points. We take $\left\|x_{n}-0\right\| \leq \varepsilon_{1}$ as the stopping criterion and $\varepsilon_{1}=10^{-12}$ in Table 1. The algorithms are coded in Matlab 2013 and run on a personal laptop. For different initial points 1, 4 and 5, the numerical results of the above algorithms (3.1), (3.10), and (3.11) are shown in Table 1. From Table 1, we observe that algorithm (3.1) is the best, from the points of view of number of iterations and running time.

TABLE 1. The numerical results of the three algorithms with $\varepsilon_{1}=10^{-12}$

\begin{tabular}{ccccccc}
\hline \multirow{2}{*}{$x_{0}$} & \multicolumn{2}{c}{ Algorithm(3.1) } & \multicolumn{2}{c}{ Algorithm(3.10) } & \multicolumn{2}{c}{ Algorithm(3.11) } \\
\cline { 2 - 7 } & Iter. & Sec. & Iter. & Sec. & Iter. & Sec. \\
\hline 1 & 45 & 0.018679 & 50 & 0.02251 & 58 & 0.027706 \\
4 & 47 & 0.018463 & 52 & 0.022052 & 60 & 0.023901 \\
5 & 47 & 0.018915 & 51 & 0.022997 & 61 & 0.026087 \\
\hline
\end{tabular}

In Table 2 and Table 3, let $\left\{x_{n}\right\}_{n=0}^{\infty}$ be the iterative sequence generated by (3.1), $\left\{y_{n}\right\}_{n=0}^{\infty}$ be the iterative sequence generated by (3.10) and $\left\{z_{n}\right\}_{n=0}^{\infty}$ be the iterative sequence generated by (3.11). The comparison 
of the convergence of algorithms (3.1), (3.10), and (3.11) to the common fixed point $p=0$ are given in Table 2 and Table 3, with the initial $x_{0}=y_{0}=z_{0}=5$.

From Table 2, we see that algorithm (3.1) converges faster than algorithms (3.10) and (3.11) by using the Definition 4.1. From Table 3, we see that algorithm (3.1) converges faster than algorithm (3.10) and algorithm (3.10) converges faster than algorithm (3.11) by using the Definition 4.2.

TABLE 2. Comparison of rate of convergence of the three algorithms by the def. 4.1

\begin{tabular}{cccc}
\hline$n$ & Algorithm (3.1) & Algorithm (3.10) & Algorithm (3.11) \\
\cline { 2 - 4 } & $x_{n}$ & $y_{n}$ & $z_{n}$ \\
\hline 10 & 0.01342 & 0.033201 & 0.13211 \\
$\vdots$ & $\vdots$ & $\vdots$ & $\vdots$ \\
45 & $2.5566 \mathrm{e}-12$ & $2.828 \mathrm{e}-11$ & $2.59 \mathrm{e}-09$ \\
46 & $1.3486 \mathrm{e}-12$ & $1.5554 \mathrm{e}-11$ & $1.554 \mathrm{e}-09$ \\
47 & $7.114 \mathrm{e}-13$ & $8.5547 \mathrm{e}-12$ & $9.3239 \mathrm{e}-10$ \\
\hline
\end{tabular}

TABLE 3. Comparison of rate of convergence of the three algorithms by the def. 4.2

\begin{tabular}{cccc}
\hline $\mathrm{n}$ & $\frac{\left|x_{n}-0\right|}{\left|y_{n}-0\right|}$ & $\frac{\left|x_{n}-0\right|}{\left|z_{n}-0\right|}$ & $\frac{\left|y_{n}-0\right|}{\left|z_{n}-0\right|}$ \\
\hline 10 & 0.4042 & 0.10158 & 0.25131 \\
20 & 0.25688 & 0.024715 & 0.096213 \\
30 & 0.16915 & 0.0068125 & 0.040273 \\
46 & 0.086704 & 0.00086782 & 0.010009 \\
\hline
\end{tabular}

\section{CONCLUSiOnS}

Three kinds of hybrid algorithms for a finite family of quasi-nonexpansive mappings were proposed in this paper. Their strong convergence was obtained in the framework of Hilbert spaces. Numerical examples were provided to compare and illustrate the effectiveness of the three algorithms. The results obtained in this paper extend some known results in the literature.

\section{Acknowledgements}

The first author was supported by the National Natural Science Foundation of China under Grant No. 61866038, PhD-Start Project of Yan'an University under Grant No.YDBK2018-09, and the Special Research Project of Shaanxi Education Department under Grant No.18JK0876. The third author was supported by the National Natural Science Foundation of China under Grant No. 11071053.

\section{REFERENCES}

[1] R. Davidi, G.T. Herman, Y. Censor, Perturbation-resilient block-iterative projection methods with application to image reconstruction from projections, Int. Trans. Oper. Res. 16 (2009), 505-524.

[2] P. L. Combettes, On the numerical robustness of the parallel projection method in signal synthesis, IEEE Signal Process. Lett. 8 (2001), 45-47. 
[3] C.I. Podilchuk, R.J. Mammone, Image recovery by convex projections using a least-squares constraint, J. Opt. Soc. Am. 7 (1990),517-521.

[4] S. S. Chang, Viscosity approximation methods for a finite family of nonexpansive mappings in Banach spaces, J. Math. Anal. Appl. 323 (2006), 1402-1416.

[5] Y. Yao, A general iterative method for a finite family of nonexpansive mappings, Nonlinear Anal. 66 (2007), $2676-2687$.

[6] Y.J. Cho, Approximation of common fixed points of an infinite family of nonexpansive mappings in Banach spaces, Comput. Math. Appl. 56 (2008), 2058-2064.

[7] L.C. Ceng, Approximation of common solutions of a split inclusion problem and a fixed-point problem, J. Appl. Numer. Optim. 1 (2019), 1-12.

[8] K. Nakajo, W. Takahashi, Strong convergence theorems for nonexpansive mappings and nonexpansive semigroups, J. Math. Anal. Appl. 279 (2003), 372-379.

[9] X. Qin, Y.J. Cho, S.M. Kang, Convergence theorems of common elements for equilibrium problems and fixed point problems in Banach spaces, J. Comput. Appl. Math. 225 (2009), 20-30.

[10] S. He, C. Yang, P. Duan, Realization of the hybrid method for Mann iterations, Appl. Math. Comput. 217 (2010), $4239-$ 4247.

[11] H. Zhou, X. Gao, A strong convergence theorem for a family of quasi- $\phi$-nonexpansive mappings in a Banach space, Fixed Point Theory Appl. 2009 (2009), 351265.

[12] H. Zhou, Convergence theorems of fixed points for Lipschitz pseudo-contractions in Hilbert spaces, J. Math. Anal. Appl. 343 (2008), 546-556.

[13] X. Qin, S.Y. Cho, J.K. Kim, Convergence theorems on asymptotically pseudocontractive mappings in the intermediate sense Fixed Point Theory Appl. 2010 (2010), Article ID 186874.

[14] P.K. Anh, C.V. Chung, Parallel hybrid methods for a finite family of relatively nonexpansive mappings, Numer. Func. Anal. Optim. 35 (2014), 649-664.

[15] Q.L. Dong, Y.Y. Lu, J.F. Yang, Cyclic hybrid methods for finding common fixed points of a finite family of nonexpansive mappings, J. Nonlinear Sci. Appl. 9 (2016), 2000-2005.

[16] H. Zhou, P. Wang, A new iteration method for variational inequalities on the set of common fixed points for a finite family of quasi-pseudocontractions in Hilbert spaces, J. Inequal. Appl. 2014 (2014), Article ID 218.

[17] I. Yamada, N. Ogura, Hybrid steepest descent method for the variational inequality problem over the fixed point set of certain quasi-nonexpansive mappings, Numer. Funct. Anal. Optim. 25 (2004), 619-655.

[18] B. E. Rhoades, Comments on two fixed point iteration methods, J. Math. Anal. Appl. 56 (1976), 741-750.

[19] V. Berinde, Picard iteration converges faster than Mann iteration for a class of quasi-contractive operators, Fixed Point Theory Appl. 2 (2004), 97-105.

[20] W. Phuenqrattana, S. Suantai, On the rate of convergence of Mann, Ishikawa, Noor and SP-iterations for continuous functions on an arbitrary interval, J. Comput. Appl. Math. 235 (2011), 3006-3014. 